IN FOLIO 



\title{
Entre prácticas reivindicativas e historias de resistencias: memorias de mujeres negras en Cuba
}

\author{
Por Muriel Vanegas Beltrán ${ }^{1}$ \\ Universidad de Cartagena (Colombia)
}

Hevia Lanier, Oilda \& Castillo, Daisy Rubiera. (Comps.). (2016). Emergiendo del silencio. Mujeres negras en la historia de Cuba. La Habana: Editorial de las Ciencias Sociales. 275 p.

En el amplio, diverso y complejo campo de los Estudios subalternos y de los Sectores populares, las mujeres negras han sido consideradas las depositarias de las más intrincadas expresiones y formas de discriminación, segregación y exclusión. Por lo tanto, las categorías de "género" y "raza" representan dos aristas que convergen en un mismo plano de análisis para deconstruir las tradicionales perspectivas patriarcales y de poder, y los marcos discursivos clasistas que hasta hace poco se venían imponiendo en el lenguaje académico, en el ámbito institucional y en la vida cotidiana.

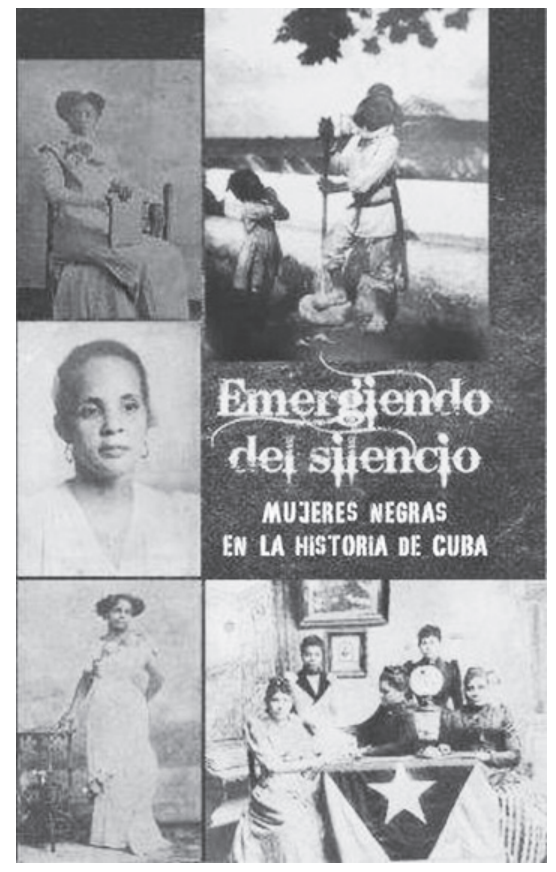

Historiadoras cubanas han trazado estos derroteros desde mediados de los años noventa con obras como La esclavitud desde la esclavitud, de Gloria García (1996); Reyita, sencillamente, de Deysi Rubiera Castillo (1996); La otra familia (2004) y Mujeres al margen de la Historia (2009), de María del Carmen Barcia, entre otras, abriendo camino para el posicionamiento de nuevos enfoques que reivindican

\footnotetext{
${ }^{1}$ Dra. en Ciencias de la Educación. Magister en Estudios del Caribe de la Universidad Nacional de Colombia. Historiadora de la Universidad de Cartagena. Docente de la Universidad de Cartagena. Investigadora del Instituto Internacional de Estudios del Caribe. Miembro del Grupo de Investigación Sociedad, Cultura y Política en el Caribe colombiano. e-mail: mvanegasb@unicartagena.edu.co
} 
e incorporan a la mujer negra como un agente histórico y actor social de capital importancia. Así mismo, notables esfuerzos abanderados por activistas u organizaciones antirracistas en la Isla, en su mayoría, fundadas y lideradas por negras cubanas, vienen visibilizando un feminismo reivindicativo que ha reincorporado a la mujer cubana, no sólo en la sociedad e historia misma, sino igualmente, y de manera fundamental, en la historiografía, rescatando así historias invisibilizadas o negadas.

"Afrocubanas" es una de tales organizaciones de reconocido compromiso social y académico, encargadas de la promoción del debate abierto e interdisciplinario que requieren estos aspectos. Este tipo de tareas buscan, en primer término, investigar los procesos que han favorecido la construcción racista de la diferencia social y de género, para luego entrar a corregir prácticas fuertemente arraigadas que van desde las más sutiles acciones cotidianas, hasta aquellas que encuentran en la historia, su más "legítimo" sustento y justificación.

Considerando, entonces, que los esfuerzos por combatir y erradicar el racismo en Cuba no son iniciativas ni intentos recientes, integrantes de "Afrocubanas" asumieron una apuesta académica que dio como fruto la obra Emergiendo del silencio. Mujeres negras en la historia de Cuba, publicada en 2016 por Editorial de las Ciencias Sociales. Se trata de una compilación de ocho ensayos que busca reconstruir la memoria histórica de las cubanas afrodescendientes, quebrantar cánones racistas de poder y aportar al enriquecimiento de la historiografía cubana sobre temáticas raciales, desde las propias voces de mujeres negras y mestizas.

En ese orden de ideas, el ensayo que abre el conjunto de textos, titulado "Historias ocultas: mujeres dueñas de esclavos en la Habana colonial (1800-1860)", de Oilda Hevia Lanier, aborda el espinoso tema de la compra y venta de esclavos por parte de mujeres negras. Teniendo en cuenta que un buen número de esclavizadas había logrado la anhelada libertad propia y de sus seres queridos a partir de grandes luchas, resulta extraño, y a la vez paradójico, encontrarlas como propietarias y comercializadoras de esclavos. Hevia explora y discute esta delicada situación, con base en las múltiples circunstancias que tejieron esta compleja realidad, y los significados derivados. Uno de sus más sólidos aportes en esta dirección es que los esclavos se ofrecían voluntariamente a fin de cambiar de dueños por los malos tratos recibidos. Siendo esta perspectiva una de las menos atendidas por los historiadores 
cubanos, queda en este capítulo evidenciada la estrecha relación entre libertad, identidad y propiedad.

El segundo capítulo corresponde a "La prostitución como estrategia de libertad en la Habana del siglo XIX. Notas para su estudio", coautoría de María de los Ángeles Meriño Fuentes y Aisnara Perera Díaz, y discute las variaciones en la práctica y representación de la prostitución que se presentaron en los contextos urbanos y rurales $\mathrm{y}$ en el trabajo callejero y doméstico, en tanto se relacionaran con condiciones particulares como el acceso a recursos legales o el apoyo hallado en terceros para iniciar un proceso legal. A la par de ello, este capítulo devela el uso frecuente que hacía de su cuerpo la mujer prostituta cubana, disponiendo de su sexualidad no sólo como un terreno de disfrute de goce, sino también como un medio de garantizar su subsistencia económica y como estrategia de libertad.

Sigue un tercer capítulo denominado "Colores y dolores en la educación femenina en Cuba (siglo XIX)", de Raquel Vinat Mata, el cual devela la importancia que tuvieron elementos como los cantos y lecciones expresados en oraciones y sentimientos en la formación de los primeros años de los niños. Desde fines del siglo XVIII, las mujeres habaneras eran las que asumían estos roles, que eran vistos como una extensión del rol de cuidadora de los niños en el ámbito doméstico. Sin embargo, iniciado el siglo XIX, el despliegue de discursos reformistas en torno a la modernización de la educación, intentó replegar la labor de educadora de la mujer negra bajo argumentos elitistas que la descalificaba para tal fin. De esta manera, se presentan una serie de casos e historias a través de las cuales las maestras lucharon por preservar esta labor, mejorando sus formación y resultados en la educación de los niños a su cargo.

"Género y los sentidos de la libertad: mujeres esclavizadas y libertas en Cuba y Brasil (1870-1888)", de Camillia Cowling, es el ensayo que continúa a modo de cuarto capítulo, el cual identifica y explica las diversas formas de luchas y resistencias femeninas para acceder a acciones legales por la libertad o a derechos sobre su propio cuerpo, en medio de las barreras o trabas que imponía la burocracia urbana. Cowling no escatima en describir y detallar los hábitos de ahorro de las mujeres en su condición de esclavitud para lograr su libertad o la de sus hijos, o en ilustrar las prácticas u oficios que forjaron un espíritu empresarial para proveerse el sustento, tales como vendedoras, parteras, curanderas y lavanderas. A la par de estos desarrollos, también se aborda en este apartado los vínculos con los que se establecieron fuertes lazos familiares y de amistades 
que les significaron la posibilidad de sobrevivir e inclusive acceder a propiedades.

Bonnie Lucero es la autora del quinto capítulo que lleva por título "Entre esclavos y comerciantes: las mujeres negras como intermediarias en la economía colonial cienfueguera". El propósito de este apartado es examinar los roles que desempeñaron las finanzas y las propiedades en la construcción de redes sociales entre las propietarias negras de Cienfuegos en el siglo XIX. Con base en fuentes como testamentos, el texto establece, con notable profundidad, cómo se construyeron y consolidaron lazos de influjo social y económico, soportados en relaciones y alianzas de amistad con los que, a partir de sus roles domésticos y empresariales, pudieron mediar entre las comunidades afrodescendientes y los círculos de población blanca de amplio poder socioeconómico.

El capítulo seis, "Mujeres en las guerras de independencia: siempre a las órdenes de la querida patria", de Damaris Torres Elers, es un análisis de actividades comerciales y de los servicios sociales que desempeñaron las mujeres cubanas afrodescendientes en movimientos de trascendencia política como las contiendas independentistas en apoyo al Ejército Libertador. Desde acciones como el traslado de víveres, medicinas y correspondencias, hasta labores de curar enfermos o participar en la logística e inteligencia de guerra, se recrean y argumentan las trascendentales contribuciones de las mujeres en las gestas libertarias, aún en medio de su carencia de una educación formal.

"El discurso femenino negro de reivindicación (1888-1958)", de Daisy Rubiera Castillo, es el séptimo capítulo, que muestra los aportes de escritoras negras orgullosas de su raza, con los cuales hacen llamados a la lucha de sus congéneres en el reconocimiento de sus diversos logros personales y sociales. "María Damasa Jova: ¿la primera delegada negra de la República?”, de Duke Dawn, es el capítulo que cierra la obra, y tal como indica su título, se basa en la escritora y literata afrocubana de la primera mitad del siglo XX, María Damasa Jova. Con una lectura analítica de sus actividades y producciones, se arguye que esta escritora representó un símbolo de resistencia desde las letras, que, con su formación positivista, desplegó un puente entre la poética y la política, arrojando así una interesante lectura y escritura que supo mostrar la interacción entre la mujer y la nación en el contexto republicano.

Con acuciosos y rigurosos trabajos de archivo y manejo de fuentes, redacciones fluidas, variados ejemplos y argumentos sólidos y 
fundamentados, los textos que integran esta obra se organizan y estructuran alrededor de las temáticas centrales referenciadas que, en sus particularidades conceptuales, metodológicas y temporales, se entrelazan con el hilo conductor de reconstruir un discurso reivindicativo y revisionista que aspira a develar el soslayado y silenciado papel de la mujer negra en la historia de Cuba, desde el siglo XIX hasta mediados del XX.

De esta manera, problemas y preocupaciones intelectuales alrededor de las rebeliones protagonizadas por esclavizados, las economías urbanas y el proyecto modernizador sustentado en la educación pública, se desarrollan en esta obra como columna vertebral de procesos atravesados por relaciones de género y raza, con resistencias, negociaciones y/o consensos en los que las mujeres negras y mestizas cubanas han sido determinantes desde tiempo coloniales. Con la recuperación de estas memorias vivas y presentes, este libro representa una seria contribución a la historiografía caribeña en sus recientes esfuerzos por contrarrestar los procesos de fragmentación y desigualdad social, en la medida en que para hacerse notar y sentir, y para dar a conocer su historia, los sectores tradicionalmente excluidos y oprimidos primero deben emerger del silencio. 
